\title{
Loss of Hue Discrimination in Forebrain-Ablated Fish
}

\author{
JERALD J. BernStein ${ }^{1}$ \\ Department of Fisheries, University of Michigan, Ann Arbor, Michigan
}

Received July 20, 1960

\begin{abstract}
The effect of forebrain ablation on hue discrimination in fish has been studied. Cardiac deceleration, a conditioned autonomic response, was used as the measure of discrimination in a series of goldfish. Electric shock was the unconditioned stimulus. Forebrain-ablated fish were trained to $a$ red and a green stimulus selected to be of equal brightness. These fish were subsequently tested on red and green stimuli of known brightness, as perceived by these experimental animals. Normal fish in this situation reacted to the test stimuli on the basis of their wavelength characteristics, but forebrainless animals reacted only to the brightness and not to the wavelength characteristics of the test stimuli. Other control tests substantiate this finding.
\end{abstract}

\section{- Introduction}

Fish have been taught to make many types of discriminations $(6,17)$. Investigators of color vision in fish have had as a persistent stumbling block their inability to control completely for the possibility that their fish were discriminating in terms of brightness instead of hue. One of the main difficulties of the former method of brightness control can be attributed to the fact that hues have different subjective brightnesses. Therefore, a brightness match of two colored stimuli made by a human observer may not have the same brightness relationship when perceived by his experimental animals $(21,23)$.

There are several papers on the effect of forebrain removal on the behavior of fishes $(5,20)$. In these papers the brain case was opened and the desired portion of the brain was removed $(8,10,13,14,24)$. After the brain was ablated the experimental fish was replaced in the test aquarium without adequate protection of the remaining portion of the

1 The author's present address is the Laboratory of Neuroanatomical Sciences, National Institute of Neurological Diseases and Blindness, Bethesda, Maryland. This work was supported by a research grant to Dr. R. A. McCleary from the Department of Health, Education and Welfare, NINDB, Grant No. B598 $\left(\mathrm{C}_{2}-\mathrm{C}_{4}\right)$ and by the Department of Fisheries, University of Michigan, Ann Arbor. 
central nervous system. The results of these experiments may have been influenced by the ionic imbalance caused by the influx of the external medium.

Effects of social facilitation upon learning ability in normal and forebrainless green sunfish show that the forebrain removal resulted in loss of all previously established associations and slowed reaction time during subsequent training (4). The effect of lesions in the optic tectum upon second-order learning in goldfish shows that ablation of large areas of the anterior border of the optic tectum caused disturbances in secondorder learning of visual and olfactory stimuli (16). It has also been found that lesions of the optic tectum in the same species has no effect on visual discrimination (18).

Previous work has indicated that forebrain ablation has no effect on color vision in fish $(8,14)$. Goldfish were trained to make a presumed hue discrimination ( 8 ) by feeding them from a receptacle of a specific hue. After a fish had learned this problem, its forebrain was removed in total and it was presented an array of gray receptacles as well as the original colored vessel. The operated fish did indeed return to the colored vessel in preference to the gray receptacles, however, the investigator did not know the brightness of the original colored vessel as perceived by the fish. Therefore the series of grays may not have included a brightness which was equal to the subjective brightness of the original colored vessel as perceived by the fish. In short, this control does not eliminate brightness as a possible cue in the discrimination.

In another study fish were also trained to make a presumed hue discrimination by feeding in one band of a complete visual spectrum, which was projected on the side of a test aquarium close to the surface of the water (14). After the fish had learned this discrimination, their forebrains were removed in part or in total. The test animals (a minnow, Phoxinus, or a stickleback, Gasterosteus) consistently returned to the spectral band to which they were previously trained, and it was concluded that forebrain ablation had no effect on hue discrimination. In this set of experiments, however, the observer determined the relative brightness of the various spectral bands by his own eye. The investigator could not be certain that the position of the spectrum to which the animal was trained did not, during the control tests, retain a unique brightness relationship to certain other portions of the test spectrum.

A new approach to the study of color vision in fish seems to circumvent the former problems (11). Cardiac deceleration, a conditioned autonomic 
response, was used as a measure of discrimination in a series of goldfish with electric shock as the unconditioned stimulus. All stimuli were standardized color-aid art papers or art papers in combination with Kodak Wratten filters. Goldfish were trained to discriminate a red and a green stimulus that had been selected to be of equal brightness. These animals were then presented a series of red and green stimulus patches of known brightness differences as perceived by the fish. Under these circumstances goldfish generalize perfectly-according to hue-despite the known brightness differences of the test stimuli.

It is this improved technique, and the use of a cranial-cap to eliminate the aqueous environment after central nervous system ablation that has been used in this research.

\section{Methods}

Materials. The 8- to 12-inch goldfish (Carassius auratus Linn.) were held individually in place in a 40-gallon aquarium for both training and testing. The method for mounting the test animals in the aquarium

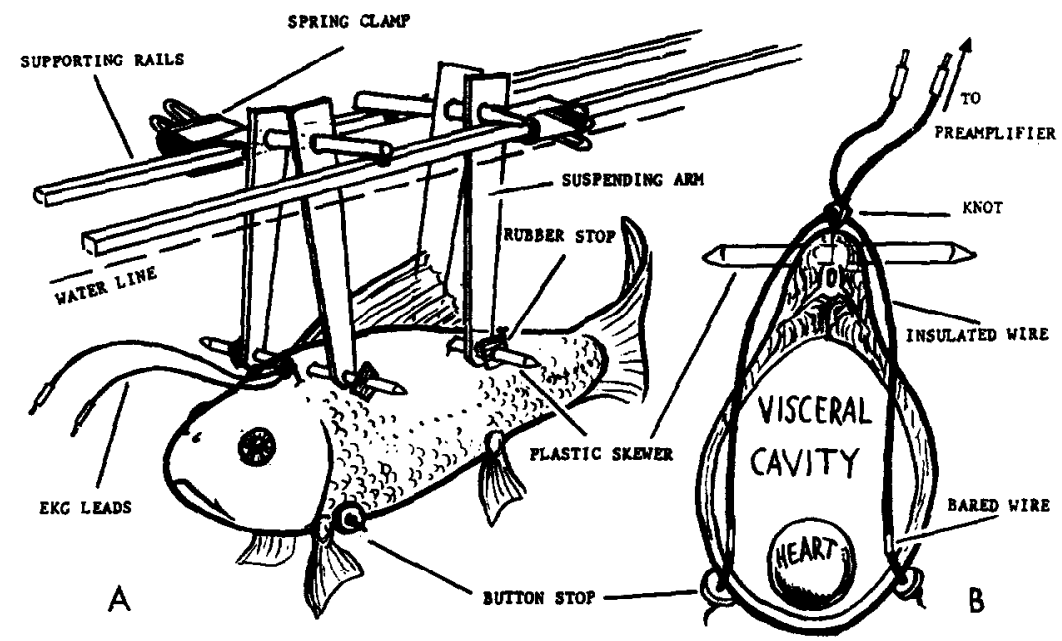

FIG. 1. A, goldfish skewered and in position for training. B, diagram of the placement of the cardiac electrodes (11).

(Fig. 1A) is the same as used in an earlier study (11). Shock was supplied by a variable, stepdown D.C. transformer. The fish, when fixed in place in the aquarium, was isolated from outside distraction by an opaque, plastic liner over the top of the aquarium. The liner was designed in such 
a way that it extended down into the water, close around the fish, with its lower edge terminating just opposite and 3 to 4 inches away from its eyes. When stimuli were introduced into the aquarium on the end of thin, transparent Lucite rods, the fish could not see the stimulus until it suddenly appeared beneath the edge of the cover-immediately opposite and about 6 inches from the eye being trained or tested.

The interior of the aquarium was lighted by a 100-watt daylight bulb housed in a flood-light casing. The light entered the aquarium through an opening in the liner to the rear of the fish. The light source was about 30 inches behind the level of the eyes of the fish.

Recording electrodes were buried bilaterally in the visceral cavity of each fish (Fig. 1B) to provide continuous electrocardiographic (ECG) records during conditioning and testing trials (11).

The stimuli were $3 / 4$-inch clear pastic squares containing colored patches in various brightnesses of red, green, and gray and were constructed of Kodak Wratten filters and/or Color-aid art papers. ${ }^{2}$ The stimuli were mounted on Lucite rods for the purpose of introducing them into the aquarium. The exact composition of each of the stimulus patches is given in Table 1 .

TABLE 1

Composition of Stimult in Phase I

\begin{tabular}{llc}
\hline \multicolumn{1}{c}{ Patch } & \multicolumn{1}{c}{ Source } & \% Reflectance ${ }^{a}$ \\
\hline Dark red & Filter No. 29 & 5.0 \\
No. 7 gray paper & 7.0 \\
Dark green & Filter no. 57-A & 37.0 \\
& No. 7 gray paper & 39.0 \\
Light red & No. 3 red tint paper & 23.0 \\
Light green & No. 3 green tint & 20.0 \\
Medium red & No. 1 red tint paper & 19.5 \\
Medium green & No. 1 green tint paper & 34.0 \\
Dark gray & No. 5 gray paper & \\
Light gray & No. 3 gray paper & \\
\hline
\end{tabular}

Measured on a Luckiesh-Taylor brightness meter, using magnesium carbonate as a reference block.

The designation of light, dark, or medium means that the stimulus patches were (as judged by human eye), respectively, lighter than, darker than, or about the same brightness as the gray background against which

2 Color-aid Swatch Book; compiled and coordinated by Sidney Beller, Copyright 1948. 
all stimuli were presented to the fish. The gray background was two opaque plastic sheets sprayed with a combination of enamel paints (Krylon gray and Krylon white) so that the resulting gray appeared to be midway in brightness between the number three and number five, gray Color-aid papers. One such sheet was placed opposite each eye of a test animal.

All surgery was performed out of water. After being anesthetized, the animal was strapped to a stand and its mouth was placed over a onehole rubber stopper. By means of storage tanks and connecting hoses, water or water containing anesthetic could be given to the animal. The

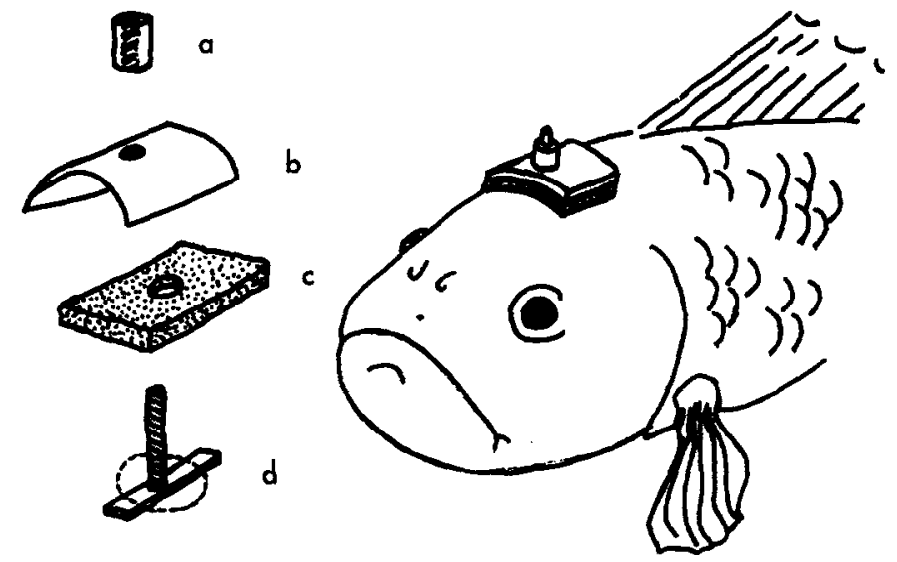

FIG. 2. The component parts of the cranial-cap and its placement after forebrain ablation; a, nut; b, metal cap; $c$, latex pad; $d$, bar and machine screw.

head was then opened with a $3 / 8$-inch trephine drill and forebrain was bilaterally removed by suction supplied from a water aspirator. Finally, the opening in the brain case was closed by a slightly curved metal cap 2 by $1 \frac{1}{4}$ inches. This cap had a hole bored in the center of it and a 1-inch, 5/40 machine screw with a 1 by $5 / 4$ inch metal bar at its end was placed through the hole in the metal cap (Fig. 2). When the cap was ready to be used, a piece of self-sealing latex, slightly larger than the cap, was placed between the cap and the bar (Fig. 2). The bar was placed in the opening in the brain case so two ends of the bar were on the interior dorsal wall of the brain case. A nut was placed on the screw which was then tightened so that the cap was pressed hard against the latex, against the cranium, and over the opening, and the bar was pulled 
against the wall of the brain case (Fig. 2). This arrangement closed the roof of the cranium so that water did not enter the brain case.

After training and testing, the brains of all operated fish were perfused, stained, and sectioned according to the pyridine silver technique (15).

Procedure. This experiment involved classical conditioning with electric shock as the unconditioned stimulus and the various stimulus patches, described above, as the conditioned stimuli. The strength of shock (4 to 12 volts) was adjusted for each fish so there was a clearly visible startle response. In any one training or testing series for a given fish, a pair of stimulus patches was employed. One stimulus of the pair (the neutral stimulus) was never paired with shock during training, whereas the other member of the pair (the positive stimulus) was always paired with shock during training. The other member of the pair (the positive stimulus) was always paired with shock during training. Training consisted of the presentation of the positive stimulus to the fish for a $5-\mathrm{sec}$ period with intermittent shock during the last $2 \mathrm{sec}$ of the presentation. After an interval of 1 min the neutral stimulus was presented for $10 \mathrm{sec}$ without shock. These stimuli were presented at random until a clear differential cardiac response developed. When the stimulus patches were presented, they were moved up and down slightly by the experimenter since quicker conditioning was found to result from presenting the stimuli in this way. During test trials, when it was desired to determine the cardiac response to the respective stimuli, both the positive and the neutral stimuli were singly presented for $10 \mathrm{sec}$ while recording the heart-beat of the fish. All stimuli were presented without shock during the testing period. The two stimuli in any test trial series were always presented in counterbalanced order $(A B B A)$ to make certain that the order of stimulus presentation had not produced temporal conditioning. The time between trials during test periods averaged somewhat longer than 1 min because it was frequently necessary to wait several minutes hefore the heart-rate of the test animals returned to a baseline level. During test trials, the heart-rate was recorded for $10 \mathrm{sec}$ before stimulus presentation and for the $10 \mathrm{sec}$ of stimulus presentation.

Experimental Design. The basic technique of the test series of this experiment was to employ "stimulus generalization" as a method of evaluating which aspect of the stimulus was being used by the fish in learning a given discrimination. This establishes the ability of forebrainless fish to discriminate hue when conditioned to a set of stimulus patches which are known to be perceived as distinctly red and green by normal 
fish (11). The two patches used during the training of the fish (designated as medium red and green) were red and green patches of equal brightness as judged by the human eye. In addition, these stimuli were judged equal in brightness to the gray background against which they were presented to the fish and are the same stimuli as used in an earlier study (11). Three forebrain-ablated fish were trained with the medium green patch as positive and the medium red as neutral whereas the stimuli were reversed for the other three forebrainless fish. Two normal fish were trained, one with the medium red patch as positive and the other with medium green as positive.

The details of the patches used during the training and testing are given in Table 2. Under the heading "Training Stimuli," the designation of "positive" and "neutral" indicates which member of a given stimulus pair was paired with shock during training and which was not. With regard to the "Test Stimuli" with which no shock was ever paired, the designation of "positive" and "neutral" only refers to how the various patches were regarded for the purpose of pooling the heart-rate data as presented in the Results section.

Checks for cardiac conditioning were run during the training series after each ten conditioning trials and consisted of separate 10-sec presentations of the positive and neutral stimuli. No shock, of course, was used during any test trials. Under this type of training, satisfactory conditioning of the heart-rate occurred in from ten to thirty-five trials (a single stimulus presentation being counted as one trial). After satisfactory conditioning was achieved, the fish were subjected to the final test procedure.

This consisted of presenting one at a time a pair of red and a pair of green stimuli of which one member of the pair was darker than the gray background and one member lighter than the gray background against which they were presented. These test stimuli have already been studied in previous work and are known to have, for the fish, the relative brightnesses for which they were selected (11). These four stimuli were presented twice each in counterbalanced order (ABBA). It was planned that the nature of the cardiac responses to the dark red and dark green, and light red and light green stimuli would indicate whether the forebrain-ablated fish had discriminated hue as a normal fish would when presented these stimuli in the same situation (11), or whether they had discriminated the training stimuli on the basis of brightness. Four forebrainless and two nonoperated fish were also tested with two gray stimuli 


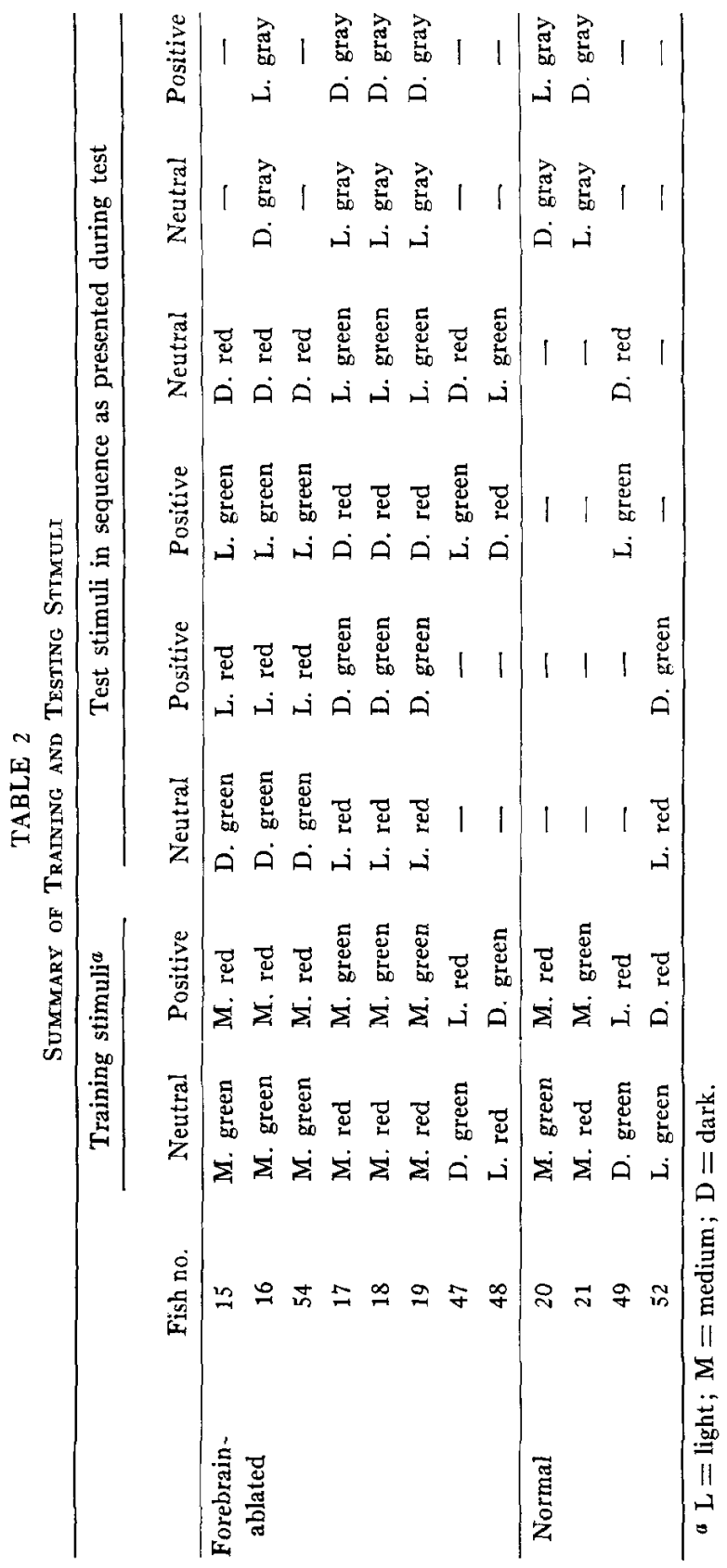


in order to ascertain whether the original medium red and green were truly equal in brightness to the fish (Table 2). Finally, two nonoperated animals and two forebrain-ablated animals were trained either to the dark red, light green patches or to the light red, dark green patches, with one member of either pair as the positive stimulus. If one of these pairs of patches was the training stimulus, the other member of the pair was the testing stimulus. In this way the brightness of the hue was actually reversed between training and testing for these four fish. The response of these animals would show if the test animals had discriminated the brightness or hue characteristic of the complex training stimuli which varied in both brightness and hue (Table 2).

\section{Results}

Forebrain-ablated fish respond to the brightness and not to the wavelength characteristics of the test stimuli. The mean results of the test trials for six fish $(15,16,17,18,19,54)$ are shown in Fig. 3. Each pair

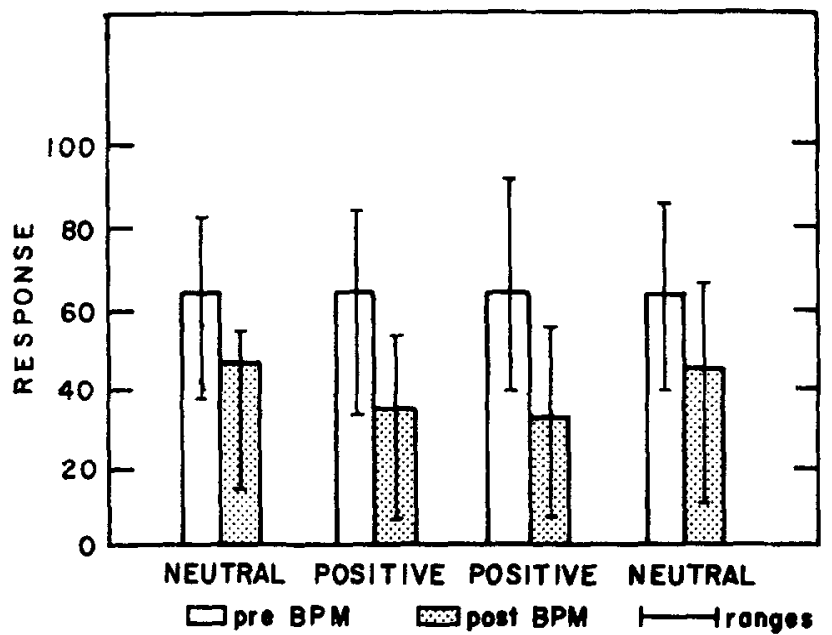

Fug. 3. Mean heart responses in beats per minute for brightness discrimination in six forebrain-ablated fish (48 test trials; $p=0.01,23 d . f$.).

of the four pairs of bars represents the heart-rate before and during stimulus presentation for one of the stimulus conditions in the series of four presentations that made up one test sequence. Since each of the six fish in this section was given two test sequences, each separate bar represents the average of twelve 10 -sec readings. The four pairs of bars represent the average of forty-eight test trials. 
Let us consider the responses of one animal. During the training period, the medium red patch was paired with shock (positive stimulus) whereas the medium green patch was presented to this fish without shock (neutral stimulus). For the first series of test trials, therefore, the dark red and light green patches were the neutral and positive stimuli, respectively. For the second series of test trials for this fish, the light red and dark green patches were the positive and neutral stimuli, respectively. In other words, once it was known that these forebrain-ablated fish would generalize according to the brightness of the training stimuli (the medium red stimulus appearing brighter to the fish than the medium green stimulus), the test stimuli were categorized as positive and neutral according to brightness in order to facilitate the combining of results, as shown in Fig. 3. Two such test series for each of the six fish in this section made up the data for Fig. 3 in which the cardiac responses are presented in the counterbalanced order (i.e., neutral, positive, positive, neutral), and in which the stimuli were presented in the tests for each fish.

The responses to the positive stimuli were larger than to the neutral stimuli (mean values Fig. 3 ). A $t$-test of the difference $(23 d . f$.) is significant at better than the 0.01 level. Both those fish trained to the medium red patch and the medium green patch contribute to this significant difference. The $p$-value presented with all figures results from a $t$-test of the difference between the cardiac responses to the neutral stimuli and the cardiac responses to the positive stimuli. A cardiac response is measured by the difference between the average heart rate $10 \mathrm{sec}$ before stimulus presentation and the average heart rate during the $10 \mathrm{sec}$ of stimulus presentation. Considering those fish trained only to the medium red stimulus as positive, this difference in Fig. 3 is at less than 0.01 level of significance. For fish trained to the medium green stimulus as positive, this difference is also significant at less than the 0.01 level.

The forebrainless fish discriminated these stimuli on the basis of the brightness characteristics of the training stimuli and not on the basis of wavelength (i.e., the designation of the test stimuli as positive or neutral was based on brightness, but the hues were reversed). For example, an animal trained to medium red as the positive stimulus and medium green as the neutral stimulus, showed greatest cardiac deceleration to the light red and light green patches and not to the dark red and dark green patches. It appears, then, that forebrainless fish when trained to the medium red patch as the positive stimulus reacted as if this stimulus patch was lighter than the gray background. Furthermore, animals 
trained to the medium green patch as positive reacted as if this stimulus patch was darker than the gray background.

It should be mentioned that normal goldfish in the same situation consistently react to the identical test stimuli on the basis of their zeravelength characteristics (11). Forebrain-ablated animals on the other hand, reacted on the basis of the brightness characteristics of the same test stimuli.

Direct experimental confirmation of the relative brightnesses of the medium red and medium green stimuli has been obtained. When trained

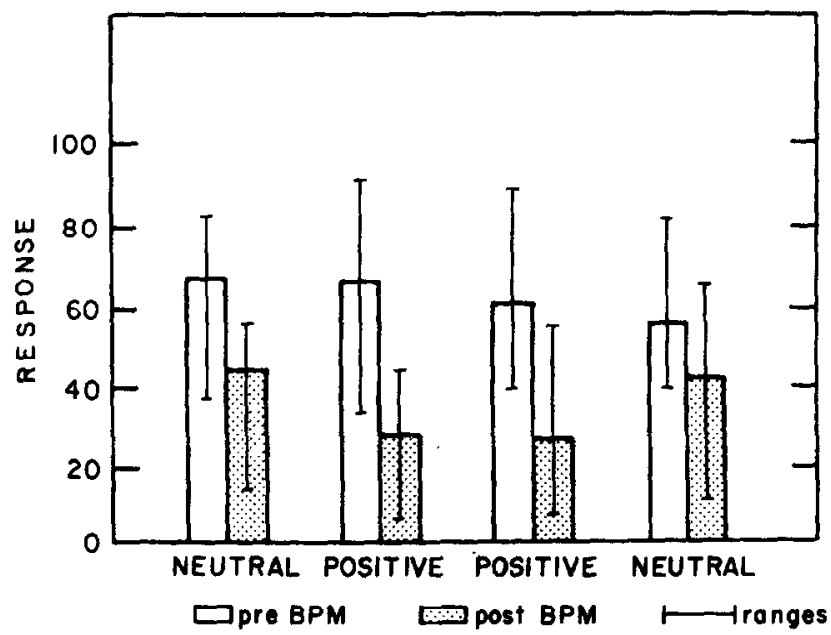

Fic. 4. Mean heart responses in beats per minute for brightness discrimination in four forebrain-ablated fish (16 test trials) trained to medium red and medium green ( $p=0.01,7$ d.f.).

to medium red and medium green, forebrain-ablated fish clearly generalized to the relative brightness of gray stimuli, whereas normal (nonoperated) fish did not react in a consistent manner to the brightness differences of the same gray test stimuli: The mean results for the four forebrainless fish $(16,17,18,19)$ are shown in Fig. 4. The bars bear the same relationship as in the former section but light and dark gray patches were the test stimuli (presented in two counterbalanced series) after training with either medium red or medium green as the positive stimulus and the other member as the neutral stimulus (Table 2).

A $t$-test of the difference in response to the positive and neutral stimuli is significant at better than the 0.01 level $(7 d . f$.$) . Of the sixteen test$ 
trials that make up Fig. 4, four trials are the test trials of forebrainablated animal 16 (trained to the medium red patch as positive, greatest cardiac deceleration to the light gray patch) and twelve test trials are from forebrainless animals 17,18 , and 19 (trained to the medium green patch as positive, greatest cardiac deceleration to the dark gray).

Responses of the two nonoperated fish were inconsistent in comparison to those of forebrain-ablated individuals. The mean results for the two normal (nonoperated) fish are shown in Fig. 5. Even though the training and testing stimuli are identical to those used with the forebrainless

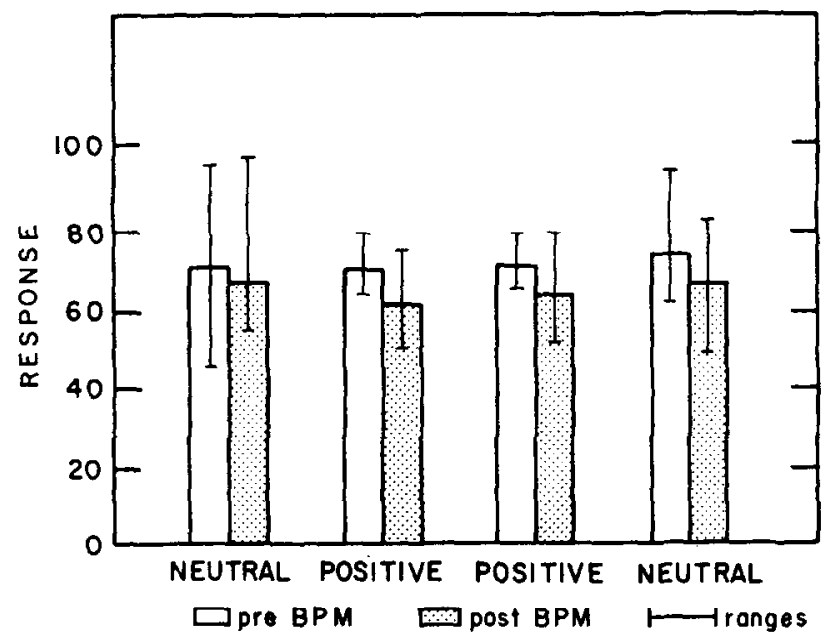

FIG. 5. Mean heart responses in beats per minute for brightness discrimination in two normal fish (24 test trials) trained to medium red and medium green ( $p=0.4$, 11 d.f.).

fish summarized in Fig. 4, it will be noted that the responses to the positive stimuli in Fig. 5 are not significantly different from the responses to the neutral stimuli ( $p=0.4$, with $11 d . f$.$) .$

These data (Figs. 4 and 5) can be taken to mean that normal fish do not discriminate the brightness difference between the medium red and medium green stimuli. The forebrain-ablated fish, on the other hand, do discriminate this brightness difference.

Forcbrainless and normal animals were trained to red and green of various intensities and tested on red and green of reversed intensity. Under this set of conditions forebrain-ablated animals chose the brightness cue when trained to a complex stimulus which contained the two 
parameters of hue and brightness and were subsequently tested on stimuli which bore the reverse relationship of hue and brightness. On the other hand normal (nonoperated) fish, under the same circumstances, did not react to the test stimuli in any consistent manner. The mean results for two forebrainless fish are shown in Fig. 6. The stimuli used for training and testing of the fish in this section are shown in Table 2.

The responses of these animals indicate that they chose the brightness characteristics of the test stimuli as shown by the maximum reaction to the positive stimulus. A $t$-test $(11 d . f$.$) is significant at the 0.01$ level.

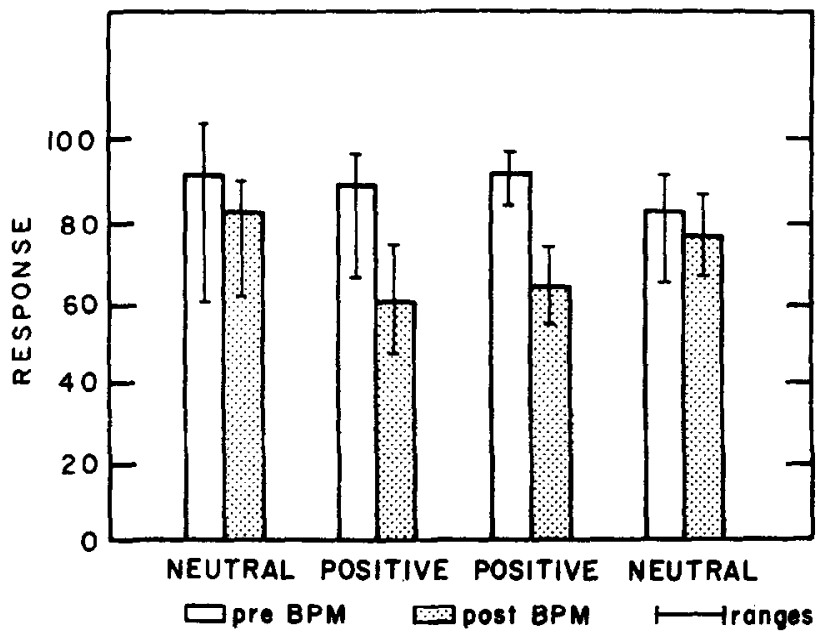

FIG. 6. Mean heart responses in beats per minute for two forebrain-ablated fish (24 test trials) trained and tested on red and green of various intensities $(p=0.01$, $11 d . f$.$) .$

That is to say, the forebrainless animal trained to light red as the positive stimulus and dark green as the neutral stimulus showed the greatest cardiac deceleration when presented the light green and not when presented the dark red. Conversely, the forebrain-ablated animal that was trained with the dark green as the positive stimulus and the light red as the neutral stimulus showed the greatest cardiac deceleration when presented dark red and not when presented light green.

Normal (nonoperated) fish did not respond to either the brightness or the hue characteristics of these same test stimuli. The mean results are presented for two normal fish in Fig. 7, where it can be seen that there is no differential cardiac response to the neutral and positive stimulus. 
The stimuli used in training and testing these nonoperated fish are shown in Table 2.

The fact that normal fish do not generalize in any consistent way to the test stimuli used to provide the data for Fig. 7 requires some comment. It is already known that when normal fish are trained to these stimuli that differ in both brightness and hue, they can subsequently generalize appropriately to stimuli differing in brightness alone or differing in hue alone (11). However, the present experiment shows that when normal fish (after such training) are tested with stimuli having the same

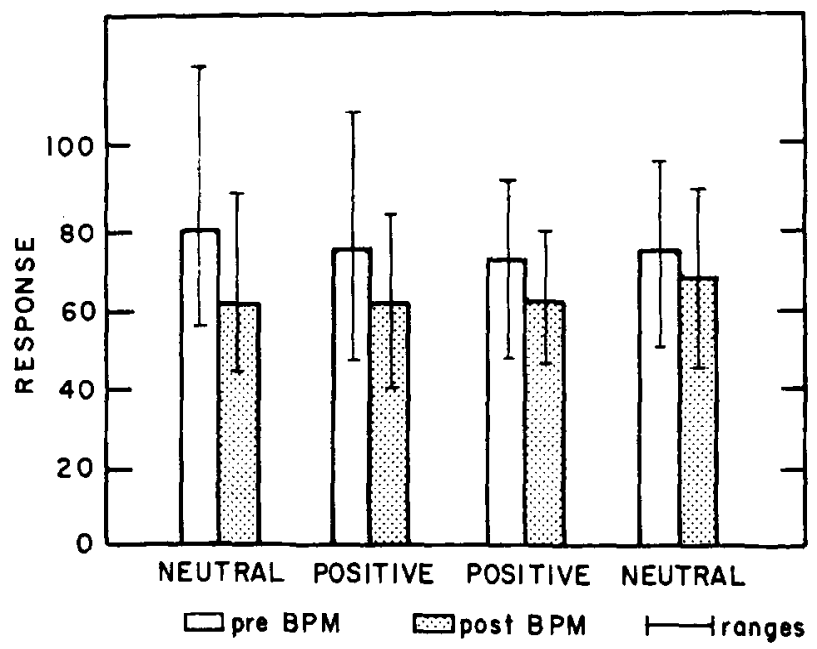

FIG. 7. Mean heart responses in beats per minute for two normal fish (24 test trials) trained and tested on red and green of various intensities $(p=0.4,11$ d.f. $)$.

hues but reversed brightness relationship, the fish becomes confused. All discrimination breaks down. This by itself is not surprising. But the important point is that the forebrain-ablated fish (Fig. 6) do not become confused in the same experimental circumstances. They generalize quite clearly in terms of the brightness differences that exist between the test stimuli. This is taken to mean that the forebrain-ablated fish did not discriminate between the hue differences of the original stimuli. (This data seems to complement the results shown in Fig. 3 where, employing different stimulus circumstances, forebrainless fish were also found not to discriminate a clearly present hue difference in the training stimuli).

Histology. Only one operated brain from the series of experimental animals was available for sectioning. The lesion resulted in total fore- 
brain ablation and damage to the most anterior border of the habenular nucleus. The nucleus preopticus, which is the border for the origin of the 'tweenbrain and the end of the forebrain in the area designated as the prethalamus $(1,2,9,12,19)$ was damaged over its rostral half, Fig. 8.

However, there was a series of twelve brains available for sectioning after identical forebrain ablation as performed in this set of experiments (3). All the brains examined showed that the extent of the brain lesion fell in the middle of the longitudinal extent of the transverse commissure and that the habenular nucleus was intact in all of those animals. Since all the ablations in both of these experiments were done in the same
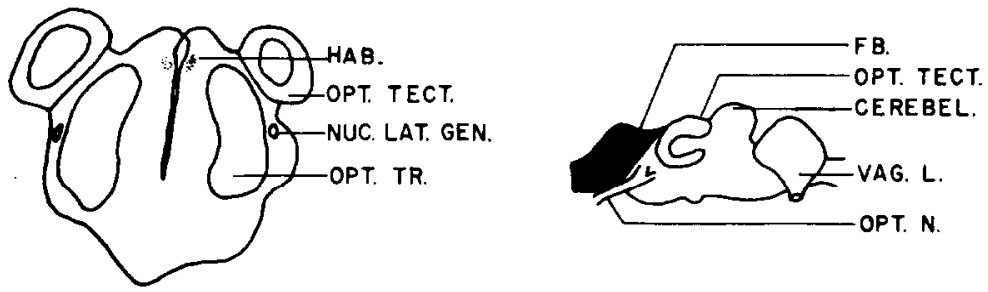

FIG. 8. Reconstructed longitudinal and cross section of the goldfish brain at the level of the anterior border of the habenular nucleus. Cerebel., cerebellum; Fb., forebrain; Hab., habenular nucleus; Nuc. Lat. Gen., nucleus geniculatum laterale; Opt. N., optic nerve; Opt. tect., optic tectum; Opt. Tr., optic tract; Vag. L., vagal lobe.

manner, and the twelve brains were all histologically alike, I can only assume that the lesions of the brains not available for sectioning would be histologically similar.

\section{Discussion}

This series of experiments has shown that under some experimental circumstances in which normal intact fish discriminate in terms of hue, the forebrainless fish select brightness differences as the basis for a learned discrimination. This finding receives indirect confirmation from additional experimental findings.

When normal fish learn to discriminate stimuli that differ in both hue and brightness their ability to discriminate breaks down when they are subsequently tested with pairs of stimuli having identical hue but reversed brightness. Such a reversal-test, however, does not confuse the operated fish since they persist in reacting to the brightness differences despite the confounding of hue-brightness relationships.

In view of this effect of forebrain removal, the question arises as to how the surgical lesion influenced the visual system of the fish. It seems 
unlikely that the removal of the forebrain, which does not possess any centers that are known to be connected directly with vision could itself be the cause of the observed phenomenon.

However, there is one thalamic nucleus, the lateral geniculate nucleus, which deserves consideration. This nucleus is innervated both by optic tract fibers (via the fasciculus dorsomedialis) and by the tractus olfactolobaris medialis from the forebrain. It is of special interest because of the suggestion that this nucleus may be involved in color vision in lower vertebrates (23). The evidence in this paper points to the fact that there may be a functional color visual system with the lateral geniculate as the central nucleus for the color visual pathway. The removal of the forebrain innervation of this nucleus could have disrupted the functioning of this system due to the loss of one of the integral portions of the pathway.

In whatever manner the experimental lesion may have produced the behavioral changes, these data indicate that such operated fish fail to make a hue discrimination even when wavelength differences are present in the experimental stimuli. The question now arises why the experimental animals continue to make a brightness discrimination. With a loss in the ability to discriminate hue (and conceivably other parameters as well) the operated fish are rendered capable of responding only to brightness differences in their environment. With visual sensitivity narrowed in such a manner, it would not be surprising if brightness differences in the training stimuli became more conspicuous to the experimental animal. It is well known for example that color-blind humans are much better able to make brightness matches between stimuli of differing wavelength (so-called heterochromatic brightness matching).

\section{References}

1. Ariëns Kappers, C. U., The structure of the teleostean and selachian brain. J. Comp. Neurol. 16: 1-109, 1906.

2. Ariëns Kappers, C. U., C. Huber, and E. Crosby, "The comparative anatomy of the nervous system of vertebrates, including man." New York, Macmillan, 2 vols., 1936.

3. Bernstein, J. J., Brightness discrimination following forebrain ablation in fish. Exptl. Neurol. (in press) 1961.

4. HaLE, E. B., Social facilitation and forebrain function in maze performance of green sunfish, Lepomis cyanellus. Physiol. Zool. 29: 93-107, 1956.

5. Healey, E. G., The nervous system. In "The Physiology of Fishes," M. E. Brown (ed.), New York Academic Press 2: 1-120, 1957. 
6. HerTer, K., "Die Fischdressuren und ihre sinnesphysiologischen Grundlagen." Berlin, Akadamie-Verlag, 1953.

7. HoRsCH, G., Untersuchungen über Grosshirnfunktionen del Elritze (Phoxinus laevis) und des Grundlings (Gobio fluviatilis). Zool. Jahrb. Abt. allgem. Zool. Physivl. Tiere 67: 57-98, 1936.

8. JANZEN, W., Untersuchungen über Grosshirnfunktionen des Goldfisches (Carassius auratus). Zool. Jahrb. Abt. allgem. Zool. Physiol. Tiere 52: 592-628, 1933.

9. KraUSE, K., Experimentelle Untersuchungen über die Sehbahnen des Goldkarpfens. Arch. mikroskop. Anat, u. Entwicklungsmech. 51: 820-839, 1898.

10. Kumakura, S., Versuche an Goldfische, denen beide Hemisphären des Grosshirns exstirpiert worden waren. Nagoya J. Med. Sci. 3: 19-24, 1928.

11. MCCleary, R. A., and J. J. Bernstein, A unique method for control of brightness cues in study of color vision in fish. Physiol. Zool. 32: 284-292, 1959.

12. Meader, R. G., The optic system of the teleost, Holocentrus. J. Comp. Neurol. 60: 361-407, 1934.

13. Meader, R. G., Notes on the function of the forebrain in teleosts. Zoologica 24: $11-14,1939$.

14. Nolte, W., Experimentelle Untersuchungen zum Problem der Localization des Assoziations vermögens in Fischgehirn. Z. vergleich. Physiol. 18: 255-279, 1933.

15. Ranson, S. W., The structure of the spinal ganglia and the spinal nerves. $J$. Comp. Neurol. 22: 159-173, 1912.

16. Sanders, F. K., Second-order olfactory and visual learning in the optic tectum of the goldfish. J. Exptl. Biol. 17: 415-434, 1940.

17. SCHulte, A., Transfer und Transpositionversuche mit monokular Dressierten Fischen. Z. vergleich. Physiol. 39: 432-476, 1957.

18. SEARs, R. R., Effect of optic lobe ablation on the visuo-motor behavior of goldfish. J. Comp. Physiol. Psychol. 17: 233-265, 1934.

19. Sheldon, R. E., The olfactory tracts and centers in teleosts. J. Comp. Neurol. 22: $177-254,1912$.

20. ten Cate, J., Physiologie des Zentralnervensystems der Fische. Ergeb. Biol. 11: $335-409,1935$.

21. Walls, G. L., The vertebrate eye and its adaptive radiation. Cranbrook Inst. Sci., Bull. No. 19: 785 pp., 1942.

22. Walls, G. L., The lateral geniculate nucleus and visual histophysiology. Univ. Calif. Publ. Physiol. 9: 1-100, 1953.

23. WARNER, L. H., The problem of color vision in fishes. Quart. Rev. Biol. 6: 329$348,1931$.

24. Wrelback, U., Untersuchungen zur Funktion des Vorderhirns bei Knockentischen. Zool. Anz. 117: 325-329, 1937. 